\title{
COMMENTARY
}

\section{Inequalities in financing of healthcare in India}

\author{
Akanksha Rathi
}

Department of Community Medicine, Dr. Baba Sahed Ambedkar Medical College and Hospital, New Delhi, India

Keywords: inequality; healthcare; financing; inverse care law

ARTICLE INFO

Received: May 7, 2017

Available online: May 15, 2017

CORRESPONDING AUTHOR Dr. Akanksha Rathi, Department of Community Medicine, Dr. Baba Saheb Ambedkar Medical College and Hospital, New Delhi, India;

akanksharathi.dr@gmail.com

\section{CITATION}

Rathi A. Inequalities in financing of healthcare in India. Trends Immunother 2017; 1(1): 50-51.

doi: 10.24294/ti.v1.i1.44

\section{COPYRIGHT}

Copyright $(\mathcal{C} 2017$ by author(s) and EnPress Publisher LLC. This work is licensed under the Creative Commons Attribution-NonCommercial 4.0 International License (CC BY-NC 4.0). http://creativecommons.org/licenses/ by $/ 4.0 /$
The healthcare system in India has long been plagued by inequalities in utilization. Moreover, just like the inequalities in utilization, there are inequalities in financing, too. Only about $5 \%$ of the gross domestic product (GDP) in the country is allocated for health, which is miniscule as compared to other fields, such as defense, that takes up around one-fourth of the GDP ${ }^{[1]}$. Out of this $5 \%$, the government spending in health is even lower (around $2 \%{ }^{[2]}$. Policymakers have long neglected the importance of allotting greater budget for health but they should understand that focusing on health is imperative for the overall development of a country. The salient points in financing in healthcare in India are as below:

- Most of the budget goes into salaries: Out of the 2\% of the GDP spent on health, $50 \%$ of the budget goes into salaries of healthcare workers, and thus there is a constant crunch for essential medicines, equipment, training, and research and development ${ }^{[3]}$.

- Public health funding: Though preventive health should get equal importance to curative health, in India there is a large disparity in this. Public health has been long ignored, and it gets only a small amount of the corpus. Public health is important for the poor, and they are the ones who suffer from this disparity the most.

- Inverse care law: It means that those who need minimum care get most of it. There are inequalities in the provisions of quality of care. The healthcare provision centers in well-to-do areas provide better quality of care than the ones present for catering poorer communities. There is lack of funding for the latter, which results in the lack of essential medicines and in untrained manpower.

- User fees: Many centers have tried introducing user fees to make themselves self-sustaining in absence of funding or due to reduced funding. However, patients do not kindly view the introduction of user fees and it ultimately results in the reduction of the utilization of services as people look for other free options.

- Equity impact of programs is ignored: A program should benefit the poor the most; only then will their health be able to match up to that of the rich someday. However, when all programs are rolled out, their equity impact is ignored. Reproductive and Child Health $(\mathrm{RCH})$ services serve all wealth quartiles the same way, but due to the limited access to the lower-wealth quartile for the utilization of the services, they are not able to benefit much from it. Hence, the maternal and infant mortality in the lower strata still remains grim.

\section{Cancer financing - A challenge for healthcare financing in India}

Cancer has become a crippling epidemic for India. The current prevalence of cancer is 2.5 million cases, with 700,000 new cancer patients registered every year and over 550,000 people dying each year from this disease 
in India ${ }^{[4]}$. Apart from being a life-threatening disease, cancer poses a great burden on the finances of the family. The drugs are exorbitantly costly (no generic anti-cancer drugs are available) and adjuvant procedures such as bone marrow transplant, surgeries and hormonal therapy are even more costly ${ }^{[5]}$. However, despite of difficulties that cancer patients face, very few hospitals provide quality care at low price to such patients - often with the help of non-governmental organizations. Typically, cancer patients are left to fend for their own selves. Some funding for the below-poverty-line patients may also come from government schemes such as Rashtriya Arogya Nidhi (RAN), but there is no respite for families that do not fall into this category. Thus, it becomes imperative to buy insurance for cancer, as about $80 \%$ of expenditure on healthcare in India is out of pocket ${ }^{[6]}$. Each year, many families are pushed down the poverty line due to healthcare expenditures and cancer is a significant disease factor falling into that category.

Immunotherapy in India is a new class of cancer treatment that is also known as biologic therapy or biotherapy. It enhances the body's immune system to fight against cancer ${ }^{[7]}$. There are several types of immunotherapy like biologics (cytokines and monoclonal antibodies) and vaccines. Some results might be encouraging but long-term survival in patients is not known. Many molecules are just a few years old and immunotherapy can burn a large hole in the pocket. This new therapy is a far-fetched dream for general public and accessible only to those who are spending a fortune in big corporate hospitals.

The healthcare financing can be improved through the prioritization of healthcare, especially primary healthcare, as well as through increased tieups with non-governmental organizations (NGOs), increased focus on public-private partnership, improved insurance coverage for particularly the marginalized population, voucher system, con- ditional cash transfer, better human resource management and political will. Policy changes, increased involvement of NGOs and government schemes providing financial aid to all cancer patients are required to ease the financial burden of this disease in the country.

\section{References}

1. With $6 \%$ GDP expenditure on healthcare, India among bottom five - A big opportunity for e-Health [Internet]. YourStory [updated 2014 Feb 1; cited 2017 May 11]. Available from: https://yourstory. com/2014/02/india-healthcare-report-opportunity/.

2. India's health woes: Budget for the National Health Mission remains stagnated at Rs 19,000 crore [Internet]. India Today [updated 2016 Mar 2; cited 2017 May 11]. Available from: http://indiatoday. intoday.in/story/indias-health-woes-budget-for-thenational-health-mission-remains-stagnated-at-rs19-000-crore/1/609824.html.

3. WHO. The World Health Report 2006: Working together for health. Geneva: WHO; 2006.

4. Nandakumar A. Consolidated report of the population based cancer registries 1990-96 [Internet]. New Delhi: National Cancer Registry Program, Indian Council of Medical Research. [updated on 2009; cited on 2017 May 11]. Available from: http://www.icmr.nic.in/ncrp/ncrp_p/ cancer_reg.pdf.

5. Tran BAP, Alexander T, Somani AK. Biochemical pathways and targeted therapies in basal cell carcinoma. J Surg Dermatol 2017; 2(1): 23-34. doi: 10.18282/jsd.v2.i1.64.

6. Mukerji C. Can you bear the cost of cancer? [Internet]The Times of India. [updated $2015 \mathrm{Jul}$ 6; cited 2017 May 10]. Available from: http:// timesofindia.indiatimes.com/business/personalfinance/Can-you-bear-cost-of-cancer/articleshow/ 47954246.cms.

7. Abdel-Rahman O. Immuno-oncology: A changing paradigm in cancer therapy. Adv Mod Oncol Res 2016; 2(6): 299-301. doi: 10.18282/amor. v2.i6.187. 